This communication is published by permission of the Director of the Atomic Energy Research Establishment.

Atomic Energy Research Establishment,

A. Charlesby

Harwell, Didcot, Berks.

Jan. 4.

${ }^{x}$ Charlesby, A., Nature, 171, 167 (1953) ; Proc. Roy. Soc., A, 215, 187 (1952). Symposium on Ttilization of Radiation from Fission Products, A.E.R.E. Report C./R. 1231 (February 1953).

2 Lawton, E. J., Bueche, A. M., and Balwit, J. S., Nature, 172, 76 (1953).

${ }^{3}$ Charlesby, A., Proc. Roy. Soc., A, 222, 60 (1954).

1 Barry, A. J., J. App. Phys., 17, 1020 (1946).

\section{Some Effects of Irradiation on Nylon and Polyethylene Terephthalate}

IN a detailed paper by Charlesby ${ }^{1}$ on the effects of irradiation on polyethylene, he suggested that the main effect was 'cross-linking', that is, the formation of covalent bridges between neighbouring molecular chrins, with the consequent loss of hydrogen. Since then, there has been a tendency to refer to the effect on any polymer as 'cross-linking' when low irradiation doses show changed solubilities in normal solvents, increased melting points, and no gross chemical breakdown ${ }^{2}$, although other possible causes for these changes have been suggested ${ }^{3}$. It seems appropriate, therefore, to describe experiments on two of the polymers which have been specifically mentioned by Charlesby and Lawton, 66 nylon and 'Terylene'.

66 Nylon. Specimens of oriented 66 nylon were irradiated in B.E.P.O. with a dose of approximately $5 \times 10^{18} \mathrm{n} . / \mathrm{cm}^{2}$, together with the associated $\gamma$-radiation. This was fifty times the dose which first affected its solubility. Observations were that hydrogen was evolved as a gas at a rate which decreased as the dose increased. Groups of atoms were broken off and formed low-molecular weight compounds which could be extracted. On X-ray diffraction photographs of an oriented specimen, the crystallites (possibly 50 per cent of the whole) appeared to be unaffected. The strength of the irradiated material was lower than the original; but subsequent experiments have shown that complete loss of strength did not occur until after an irradiation dose sufficiently high to disrupt the crystallites.

On swelling in formic acid, diffraction photographs of the highly swollen nylon showed that the crystallites had entirely disappeared, so that the nylon together with formic acid could either have been a two-phase system, or else the nylon molecules were held together with a few loose covalent bridges. On washing with water and drying, new unoriented crystallites were formed. The degree of crystallinity was less (about 30 per cent possibly), while the intensities and spacings of the diffraction rings were consistent with the new crystallites being methylsubstituted nylon. This unoriented nylon could be oriented by stretching the specimen by an amount similar to that required to draw normal unoriented nylon. On putting the irradiated nylon, which was already highly swollen in formic acid, in a mixture of formic acid with a fow per cent. of hydrochloric acid, immediate solution took place (under these conditions neither peptide bonds nor $-\mathrm{CH}_{2}-\mathrm{CH}_{2}-$ bonds would be broken). After reprecipitation in water, the polymer had the same properties, and on casting a film rather less than $200 \mathrm{~A}$. in thickness for examination in the electron microscope, it was found that the densities of the crystalline and non-crystalline regions were practically the same-as would be expected for an alkyl-substituted polyamide.

On irradiation of 66 nylon in the presence of air, there was a rapid loss of strength, and an analysis by British Nylon Spinners. Ltd., showed a very considerable increase in - $\mathrm{COOH}$ end-groups (private communication).

Polyethylene terephthalate. The behaviour of polyethylene terephthalate (or 'Terylene') is completely different. To begin with, hydrogen and other gases are not evolved in appreciable quantities. Specimens of polymer chips and fibre were irradiated with approximately $1.5 \times 10^{18} \mathrm{n} . / \mathrm{cm} .^{2}$. After this dose the fibres had completely lost their strength and begun to powder, while the chips were brittle. In specimens which were originally well crystalline the diffraction patterns looked much the same. This may be contrasted with the behaviour of 66 nylon. One polymer specimen was irradiated which had been prepared in an almost completely non-crystalline condition, and after irradiation the chips were still non-crystalline. They were then annealed at $140^{\circ} \mathrm{C}$. for $1 \mathrm{hr}$., after which X-ray diffraction showed the pattern of normal well-ordered polyethylene terephthalate. This suggests $(a)$ that extensive bridge formation could not have occurred, since any such tight linkage would inhibit the movement of molecules relative to one another, and $(b)$ that a large number of side-groupings did not occur, since they would have shown in the diffraction pattern. The results are consistent with a straightforward breakdown of the polyethylene terephthalate chains, the breakdown products having sufficient rigidity to maintain their original positions to a fairly large extent.

End-group analyses by Imperial Chemical Indus. tries, Ltd. (private communication), have shown an interesting difference, according to whether irradiation breakdown took place in the presence or absence of air. In the absence of air, there is a large increase in the number of - $\mathrm{COOH}$ end-groups, whereas in the presence of a plentiful supply of air the extra endgroups were found to be $-\mathrm{OH}$ and $\mathrm{C}=\mathrm{O}$, as in an aromatic aldehyde or ketone. This suggests that the molecular chains break in different places in the two cases.

I wish to thank British Nylon Spinners, Ltd., and Imperial Chemical Industries, Ltd., for providing samples of polymers.

\section{K. Littie}

Atomic Energy Research Establishment, Harwell,

Dideot, Berks. Feb. 11.

${ }^{1}$ Charlesby, A., Proc. Roy. Soc., A, 215, 187 (1952).

${ }^{2}$ Charlesby, A., Nature, 171, 167 (1953). Lawton, E. J., Bueche, A. M., and Balwit, J. S., Nature, 172, 76 (1953).

${ }^{3}$ Little, K., Nuture, 170, 1075 (1952).

\section{High-energy Microturbulence in the Solar Photosphere}

The Balmer, Paschen and Brackett lines of hydrogen in the solar spectrum are much wider than they should be according to computations based on the classical widening mechanism of the hydrogen

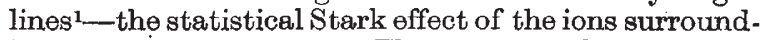
ing the emitting atoms. The amount of widening is 